\title{
E-POLITENESS: AN ANALYSIS OF TAIWANESE EFL LEARNERS' EMAIL DISCOURSE ON REQUEST STRATEGIES
}

\author{
CHIA-TI HEATHER TSENG ${ }^{1}$ \\ Ming Chuan University (Taiwan)
}

\section{ABSTRACT}

This study aims to investigate EFL learners' interlanguage pragmatic development through the elicited request emails addressed to the faculty in an institutional setting. Sixty Taiwanese students of two linguistic levels (i.e., high-intermediate, and low-intermediate) were included and different email tasks with varied imposition levels were designed to examine if and how students' use of request strategies and politeness features would vary accordingly. In total, 180 emails were composed for qualitative and quantitative analysis. By applying Blum-Kulka, House and Kasper's (1989) CCSARP framework, the results revealed that students of both levels adopted more direct strategies as main requestive head acts for clarity and used the most numbers of supportive moves prior to the request in the highest imposition request. Different combinations of supportive moves were also adopted for different request tasks by the two groups, indicating students' awareness of different imposition levels inherited in different tasks. In addition, the high-intermediate proficiency group displayed more varieties of internal and external modifiers in their request than their less proficient counterparts. Some developmental sequences in the use of politeness features can thus be identified. However, certain syntactic and lexical downgraders never appeared in both groups' email messages, suggesting the need for explicit instruction. From the preferred use of direct strategies, supportive moves, as well as a pre-posed request sequences, L1 pragmatic transfer can be observed in the email messages of both groups. The possible perlocutionary effect of this transfer will be further explored in this study. The findings in this study can provide practical suggestions for classroom intervention, particularly in the area of pragmatic instruction in EFL classrooms.

Key words: Interlanguage, Requestive Head Act, Supportive Moves, Internal/ External Modification, Perlocutionary Effect.

\section{Introduction}

Over the past decade, researchers have become interested in examining the usage of e-mail by second language learners. Studies have investigated how L2 learners compose e-mail messages in terms of communication strategies and discourse styles (Biesenback-Lucas, 2005, 2006a, 2007; Chapman, 1997;

\footnotetext{
1 E-mail: trendy656@yahoo.com.tw
} 
Chen, 2001, 2006; Gonzalex-Bueno, 1998; Hartford \& Bradovi-Harlig, 1996; Siu, 2008). Hartford \& Bradovi-Harlig's (1996) study particularly focused on e-mail requests written by college students (native and nonnative speakers of English) to faculty and analyzed the perlocutionary effects of these e-mails on the faculty and professors. They discovered that nonnative speakers used fewer politeness strategies and thus, their requests were considered less effective than those written by native speakers. In comparing native and nonnative students' email requests to faculty, Biesenback-Lucas (2007) found that although native and nonnative students tended to use the same general strategies, nonnative students' use of politeness strategies was characterized by a mix of "lack of linguistic flexibility and idiomatic expressions, unawareness of letter conventions transferrable to email, and inability to select appropriate lexical modification" (p.74).

It is apparent that writing emails to professors requires sophisticated use of language on the part of L2 learners since it is a type of FTA. The difficulty can be further complicated by the issue of cross-linguistic and cross-cultural differences between the addresser (i.e., the nonnative student) and the addressee (i.e., the English professor) (Chen, 2001).As most of the previous research effort were made in the target language environment, the research result obtained may have its limited implication in the EFL context. In addition, the results of previous research were mainly interpreted from the professor's perspective and hence, the more fundamental causes as why non-native students chose to use certain politeness strategies for their requests were still not fully understood. Furthermore, most studies conducted in the L2 environment were of comparative nature, in comparing how nonnative speakers differed from native speakers in their realization of request strategies. Kasper (1992) pointed out that most interlanguage pragmatic research were comparative rather than acquisitional in nature and thus, little has been known about how L2 learners develop their pragmatic competence over time. By conducting interlanguage pragmatics research cross-sectionally or longitudinally, the result obtained would be more acquisitionally oriented, and thus, shed more light on the developmental aspects of pragmatic acquisition.

Finally, research specifically looking at the EFL learners' pragmatic competence in writing e-mail request to faculty in the Chinese EFL context is relatively scarce, and thus, the current study aims to explore Taiwanese EFL Learners' pragmatic competence in their email request to professors. Specifically, it sets to find out EFL learners' use of requestive head act, the internal and external modifications, and the information sequencing in their emails. In order to gain more insights on the acquisitional aspect of interlanguage pragmatics, students with varied proficiency levels, from lower- intermediate to higher- intermediate, were included in the current study. To see how imposition level would impact on students' request strategies, different writing tasks varied in imposition levels were designed to examine if students' request strategies would vary with increasing imposition of the request. Finally, to understand further why these EFL students chose certain politeness strategies in their emails, open-ended questionnaires and semi-structured interviews were administered to see what factors influenced their choices of linguistic politeness strategies and what difficulties they encountered in the process of composing these email requests.

With designed writing tasks, two groups of students varied in linguistic proficiencies were required to write request emails to their English professors in order to find answers for the following research questions: 
(1) For the higher-intermediate level students, do their emails to their English professor promote more direct or indirect request strategies? Do their use of request strategies and politeness features vary with increasing imposition of requests?

(2) For the lower-intermediate level students, do their emails to their English professor promote more direct or indirect request strategies? Do their use of request strategies and politeness features vary with increasing imposition of requests?

(3) Are there preferred linguistic realizations by students of different linguistic levels for different request types? How do they differ in terms of the realization of request strategies and politeness features in their email requests?

(4) For these EFL learners, what are the factors which might influence their choices of linguistic politeness strategies used and what difficulties do they encounter in the process of composing these email requests?

\section{Review of related literature}

\subsection{Interlanguage Pragmatics}

With the notion of communicative competence introduced by Hymes (1979), the study of interlanguage has been expanded from the grammatical to the functional and communicative aspects of learner language. Thus, much research effort has been devoted to the study of interlanguage pragmatics (ILP), the "nonnative speakers' comprehension and production of speech acts, and how their L2-related speech act knowledge is acquired" (Kasper \& Dahl, 1991, p. 216). To date, most ILP studies have been conducted by comparing whether NNSs differ from NSs in the range, contextual distribution of strategies and linguistic forms used to convey illocutionary meaning and politeness. Kasper (1992) pointed out that these issues are mainly "sociolinguistic" in nature and "to a much lesser extent a psycholinguistic [or acquisitional] study of NNS' linguistic action (p.205). Likewise, Tahahashi (1996) and Bardovi-Harlig (2001) pointed out that many interlanguage studies are comparative rather than acquisitional in nature, as subjects in these studies are often grouped by their first language as nonnative speakers instead of their level of language proficiency as learners. Thus, to gain a clearer picture of how learners' ILP develop over time, a cross-sectional study, which looks at language features displayed by learners of different linguistic proficiency could be employed to further our understanding of the developmental aspect of ILP.

\subsection{Pragmatic Transfer}

Previous research has shown that when interacting with native speakers of target language, L2 learners tend to realize different speech acts by transferring the sociolinguistic and/ or sociocultural norms of their own native languages. According to Thomas (1983), when L2 learners pragmatically transfer their L1 sociocultural 
rules to the target language and when they fail to understand or to be understood the intended force of the utterance, "pragmatic failure" would occur. In fact, many negative stereotyping of different ethnic groups is also the result of pragmatic failure in cross-cultural communication.

As for the role of linguistic proficiency in relation to pragmatic transfer, consensus has not been reached. Some pragmatic studies suggest both lower level and more advanced learners transfer their $L 1$ pragmatics to $L 2$, yet advanced learners engage in more negative transfer because they are equipped with more linguistic tools to do so (Beebe \& Takahashi, 1989; Cohen \& Olshtain, 1981; Tanaka, 1988; Trosborg, 1987). Other studies did not find any effect of proficiency on pragmatic transfer, as Takahashi (1996) indicated both lower and higher proficiency learners in his study equally relied on their L1 request strategies.

\subsection{Research on E-mail Request}

By using the authentic data based on naturally-occurring requests, the available studies on actual email messages, due to the privacy and ethical reasons, have been mostly based on limited number of messages sent to the researchers themselves (Biesenbach-Lucas, 2006a, 2007; Hartford \& Bardovi-Harlig, 1996; Warschaur, 1999). Analyzing from professors' perspective, Hartford and Bardovi-Harlig (1996) investigated how native and nonnative students composed email messages in terms of communication strategies and discourse styles. They found that in comparison, nonnative students used fewer downgraders in their requests, mentioned personal time needs more often, and acknowledged imposition on faculty less often, which lead to negative perlocutionary effect on the faculty.

Chen's study (2001) compared the request emails to professors by Taiwanese overseas students and American students to identify the preferred request strategies by these two particular cultural groups. She discovered that both groups preferred to use 'query preparatory' (e.g., can you..) and 'want statements' (e.g., I want/ would like to..) to realize their requests, but they differed in the amount of lexical or syntactic mitigating features (e.g., please, possibly, I was wondering if, etc.), which made native speakers' requests more indirect and polite. Chen (2006) later conducted a longitudinal case study to investigate how two Taiwanese graduate students' email request to their professors changed over two and a half year stay in US. She discovered that students' request strategies changed from primarily 'want statements' to 'query preparatory strategies' and the email messages contained more lexical and syntactic modifications. She also pointed out that a nonnative student chose to adopt direct over indirect forms was their false belief that by making their messages sound urgent, their professors would more likely to attend their messages.

Biesenbach-Lucas (2007) examined the email requests sent by native and nonnative English graduate students to faculty. By varying the level of imposition and holding the other two factors constant (i.e., distance and power), she discovered that both groups selected more direct strategies for the lower imposition requests, but not for the highest imposition requests, an indication of students' awareness of situational factors (Biesenbach-Lucas, 2007). In addition, she found that nonnative students used less syntactic modifications, but more lexical modifications (particularly please) than native speakers. Biesenbach-Lucas concluded that 
nonnative speakers' request strategies showed "a lack of the linguistic flexibility and idiomatic expressions and an inability to select appropriate lexical modifications" (2007, p. 74).

\section{Methodology}

\subsection{Participants}

In total, sixty sophomore students enrolled in the general English courses participated in this study. Based on students' Toeic scores (or the equivalent TOEFL or GEPT scores), they were grouped as higher-intermediate level group and lower-intermediate level group.

Higher-intermediate level group were students with Toeic scores ranged between 680 to 850 , and lower-intermediate level group were those with scores ranged between 350 to 520 .

Students' mother tongue was mostly Mandarin Chinese, and on average, they have studied English for 12 years. Most of them (93.3\%) have never studied in English-speaking countries and the relatively few (6.7\%) who did, had studied there for less than a month. In addition, the female and male ratio (27:3) was also identical to ensure the homogeneity of the two groups.

\subsection{Instruments}

The data for the present study were collected from four types of instruments: (1) a written background questionnaire, (2) three experimental email writing tasks, (3) a retrospective open-ended questionnaire, and (4) the semi-structured interview. A background questionnaire was used to gather the demographic information about the participants. As for the three writing email tasks, they are varied in the levels of imposition on the professor. The three writing tasks are: the first topic (i.e., requesting for bending rules) with the highest imposition, the second topic (i.e., requesting for feedback on a research paper) with intermediate imposition, and the third topic (i.e., requesting for an appointment for getting advice on course matters) with the relatively lower imposition on the professor. Table 3.1 listed the makeup of the scripts collected from two groups of students. 90 email scripts across three topics were collected from two groups of students and in total, 180 email scripts were collected. 
Table 1. The makeup of the scripts collected from two groups of students

\begin{tabular}{lcc}
\hline & $\begin{array}{c}\text { Higher-intermediate } \\
\text { level students (30) }\end{array}$ & $\begin{array}{l}\text { Lower-intermediate level students } \\
(30)\end{array}$ \\
\hline Topic: Request for Bending & 30 & 30 \\
rules & 30 & 30 \\
Topic: Request for feedback & 30 & 30 \\
Topic: Request for & & \\
appointment & 90 & 90 \\
\hline Total emails & & \\
\hline
\end{tabular}

Finally, a retrospective open-ended questionnaire was also designed to identify the factors which might influence students' choices of linguistic politeness strategies and to find out the difficulties they encountered in composing these email requests. The questions included their perceptions of the imposition levels on each email task, the relative ranking on the proper degree of politeness and directness for each task, and the difficulties they encountered in the process of writing each email task. With the participants' permission, some participants were also interviewed to elaborate or clarify their answers to the questions.

\subsection{Coding Scheme and Data Analysis}

\subsubsection{Data coding}

Analysis of the email requests was based on the CCSARP framework developed by Blum-Kulka, House and Kasper (1989). Some modifications regarding the coding categories were made since some email messages included in the current study did not exist in the original CCSARP coding framework. Table 3.2, Table 3.3 and Table 3.4 listed the coding categories for main request strategies, syntactic and lexical modifiers, and supportive moves adjusted for the current study. The corresponding examples were also provided. 
Table 2. Coding categories for request strategies in the current study

\begin{tabular}{|c|c|c|}
\hline $\begin{array}{l}\text { CCSARP } \\
\text { directness levels }\end{array}$ & Request strategies & Examples \\
\hline \multirow[t]{3}{*}{$\begin{array}{l}\text { Direct } \\
\text { (least } \\
\text { ambiguous) }\end{array}$} & $\begin{array}{l}\text { (1) Imperatives } \\
\text { (2) performative }\end{array}$ & $\begin{array}{l}\text { Please take a look at my paper. } \\
\text { I request to have special consideration to let me } \\
\text { pass the course. } \\
\text { I am asking you for your help to proofread my term } \\
\text { paper. }\end{array}$ \\
\hline & $\begin{array}{l}\text { (3) Direct questions } \\
\text { (4) Want statements }\end{array}$ & $\begin{array}{l}\text { When do you have time? } \\
\text { I want to set up a meeting with you. } \\
\text { I would like to hear your comments about my paper. }\end{array}$ \\
\hline & $\begin{array}{l}\text { (5) Need statements } \\
\text { (6) Expectation } \\
\text { statements }\end{array}$ & $\begin{array}{l}\text { I will need your advice in taking this course. } \\
\text { I hope you can understand and let me pass the } \\
\text { course. } \\
\text { I hope I can have this appointment with you in } \\
\text { talking about this course. }\end{array}$ \\
\hline $\begin{array}{l}\text { Conventionally } \\
\text { indirect }\end{array}$ & Query preparatory & $\begin{array}{l}\text { Would you please read my paper in your free time? } \\
\text { I was wondering if you would give me some } \\
\text { comments on my paper. }\end{array}$ \\
\hline $\begin{array}{l}\text { Non-convention } \\
\text { al indirect } \\
\text { ( Hints) }\end{array}$ & Strong hint & Attached is my research paper. \\
\hline $\begin{array}{l}\text { (most } \\
\text { ambiguous) }\end{array}$ & Mild hint & $\begin{array}{l}\text { I am having a hard time in deciding whether I should } \\
\text { take this course or not. }\end{array}$ \\
\hline
\end{tabular}


Table 3. Coding categories for syntactic and lexical modifiers in the current study

\begin{tabular}{lll}
\hline $\begin{array}{l}\text { Internal } \\
\text { modifiers }\end{array}$ & Sub-categories & Examples \\
\hline Syntactic & 1) Past tense & I was wondering... \\
modifiers & 2) Progressive aspect & I'm hoping... \\
& 3) Embedding & I would appreciate it if you could.. \\
& & Can you take a look at my paper if you \\
& & have time? \\
Lexical & 1) Polite marker & please \\
modifiers & 2) Subjectiviser & I'm afraid..; I suggest..; I think... \\
& 3) Consultative device & Do you think you will; do you mind if; \\
& 4) Downtoner & Would it be possible.. \\
& 5) Understater & possibly; perhaps; maybe \\
& 6) Hedges & a little; a bit; just \\
& & somewhat; sort of; kind of
\end{tabular}


Table 4. Coding categories for supportive moves in the current study

\begin{tabular}{|c|c|}
\hline Supportive moves & Examples \\
\hline 1) Preparator & May I ask you question? \\
\hline 2) Precommitment & Could you do me a favor? \\
\hline 3) Grounder & $\begin{array}{l}\text { The reason that I missed so many classes was that I have to take } \\
\text { care of my grandmother in the hospital. }\end{array}$ \\
\hline 4) Acknowledge the & I know it violates the rules to miss so many classes, but could you \\
\hline imposition of the request & make an exception this time? \\
\hline 5) Promise & I promise that I will not miss any class any more. \\
\hline 6) Expectation & $\begin{array}{l}\text { I look forward to hearing from you soon. } \\
\text { I hope I can see your reply as soon as possible. }\end{array}$ \\
\hline 7) Sweetener & $\begin{array}{l}\text { You are the expert in the field so I think you are the most } \\
\text { appropriate person to give me advice. }\end{array}$ \\
\hline 8) Apology & I am really sorry for my poor attendance. \\
\hline 9) Thanking & Thank you for taking your time reading my mail. \\
\hline 10) Direct appeal & $\begin{array}{l}\text { I really hope you can understand. } \\
\text { Please understand my situation. }\end{array}$ \\
\hline 11) Imposition minimizer & $\begin{array}{l}\text { Please give me some feedback on my paper, under the } \\
\text { circumstances that it won't take too much of your time. }\end{array}$ \\
\hline 12) Importance & This paper is really important for me. \\
\hline 13) Showing the effort & $\begin{array}{l}\text { I have handed in all the assignments and have got good grades on } \\
\text { the tests. }\end{array}$ \\
\hline $\begin{array}{l}\text { 14) Giving options to the } \\
\text { addressee }\end{array}$ & $\begin{array}{l}\text { Please let me know your available time so I can remove my } \\
\text { schedule. }\end{array}$ \\
\hline
\end{tabular}

\subsubsection{Data analysis}

For the comparison of different request strategies and internal and external modification used for different imposition level tasks within groups, one-way analysis of variance (ANOVA) was conducted. Once the significant differences were found among different imposition tasks, a post hoc analysis was performed to locate the differences. Significant differences found would be an indication that students were aware of different levels of imposition inherent from different writing tasks and would project that awareness to the use of different politeness strategies and internal and external modifications. For comparison between two groups, independent t-tests were carried out to see if there were significant differences in their use of request strategies, syntactic and lexical modifiers and supportive moves. In addition, qualitative analysis was also performed to tap into the specific linguistic request realization patterns preferred by the two participating groups in varied imposition scenarios. 


\section{Results and discussions}

The results of both quantitative and qualitative data are presented and discussed in accordance with the research questions posed.

\subsection{Higher-intermediate Level Group: Directness Levels across Request Types and the Use of Politeness} Features

4.1.1 Directness levels in students' e-mail messages across request types

Table 5 displayed the comparison of the mean numbers of the different request strategies-direct, conventionally indirect (i.e. query preparatory) and non-conventionally indirect (i.e. hint) in the formulation of different request types by higher level students. As seen on Table 4.1, only the use of query preparatory was significantly different across different request types. The result of post hoc analysis indicated that students used significantly less query preparatory for the highest imposition request $(M=0.27)$ in comparison with the medium level imposition request $(M=0.63)$.

Table 5. Comparison of frequency usages of main request strategies across request types by higher level

\begin{tabular}{|c|c|c|c|c|c|c|c|c|}
\hline \multirow[t]{2}{*}{$\begin{array}{l}\text { Request } \\
\text { strategies }\end{array}$} & \multicolumn{2}{|c|}{$\begin{array}{l}\text { Req. (high) } \\
\text { rule-bending }\end{array}$} & \multicolumn{2}{|c|}{$\begin{array}{l}\text { Req.(medium) } \\
\text { feedback }\end{array}$} & \multicolumn{2}{|c|}{$\begin{array}{l}\text { Req. (low) } \\
\text { Appt. }\end{array}$} & \multicolumn{2}{|c|}{ ANOVA } \\
\hline & $M$ & $S D$ & $M$ & $S D$ & $M$ & $S D$ & $F$ & $p$ \\
\hline direct & 0.67 & 0.479 & 0.37 & 0.490 & 0.50 & 0.509 & 2.790 & ns \\
\hline query pre. & $0.27^{\mathrm{a}}$ & 0.450 & $0.63^{b}$ & 0.490 & 0.50 & 0.509 & 4.421 & $.015^{*}$ \\
\hline hint & 0.07 & 0.254 & 0.00 & 0.00 & 0.00 & 0.00 & 2.071 & ns \\
\hline
\end{tabular}

Note. Means with different alphabet letters within the same category differ significantly $\left({ }^{*} p<.05\right)$ by the post hoc Tukey test. ns= not significantly different

For the directness level of main strategies used for different request types, Table 5 showed that for the highest imposition request, higher linguistic proficiency students used most direct strategies (67\%). As for the medium level imposition request, students adopted more query preparatory $(63 \%)$ as their main request strategy. For the lowest level imposition request, students resorted to direct strategies $(50.00 \%)$ as much as to query preparatory $(50.00 \%)$ as their main request strategies.

As for the types of direct strategies used, Table 6 showed the subcategories of direct strategies adopted by higher level group across three request types. The totals in Table 6 indicated that for higher level students, they resorted largely to 'expectation statements' (76.67\%) (i.e., I hope you can understand and let me pass the 
course) across all request types and the second most adopted direct strategy was 'want statements' (43.33\%) (i.e., I want/ would like to set up a meeting with you).

Table 6. Subcategories of direct strategies adopted by higher level group across request types

\begin{tabular}{llllllll}
\hline $\begin{array}{l}\text { Request } \\
\text { types }\end{array}$ & Imperatives & Performative & $\begin{array}{l}\text { Direct } \\
\text { questions }\end{array}$ & $\begin{array}{l}\text { Want } \\
\text { statements }\end{array}$ & $\begin{array}{l}\text { Need } \\
\text { statements }\end{array}$ & $\begin{array}{l}\text { Expectation } \\
\text { statements }\end{array}$ & $\begin{array}{l}\text { Total } \\
\text { direct } \\
\text { strategies }\end{array}$ \\
Rule-bending & $6.67 \%$ & $13.33 \%$ & $0.00 \%$ & $10.00 \%$ & $0.00 \%$ & $36.67 \%$ & $66.67 \%$ \\
Feedback & $0.00 \%$ & $6.67 \%$ & $0.00 \%$ & $13.33 \%$ & $0.00 \%$ & $16.67 \%$ & $36.67 \%$ \\
Appointment & $0.00 \%$ & $6.67 \%$ & $0.00 \%$ & $20.00 \%$ & $0.00 \%$ & $23.33 \%$ & $50.00 \%$ \\
Total & $6.67 \%$ & $26.67 \%$ & $0 \%$ & $43.33 \%$ & $0 \%$ & $76.67 \%$ & \\
\hline
\end{tabular}

Note: (1) The total includes all emails with different subcategories of direct strategies across three different request types. (2) Total direct strategies used include all emails contained each request type varied by levels of imposition.

\subsubsection{Politeness features in higher level students' email requests}

For the use of internal modifications, Table 7 showed that both syntactic and lexical downgraders were not used significantly different across different request types. Subjects tended to use slightly more syntactic downgraders $(M=0.83)$ and lexical downgraders for requesting for feedback $(M=0.63)$.

Table 7. Comparison of frequency usages of internal modifications across request types by higher level group

\begin{tabular}{l|llllllll}
\hline $\begin{array}{l}\text { Internal } \\
\text { modifica. }\end{array}$ & \multicolumn{2}{l}{ Req.rule-bending } & Req. feedback & \multicolumn{2}{l}{ Req. Appt. } & \multicolumn{2}{l}{ ANOVA } & \\
\hline & $M$ & $S D$ & $M$ & $S D$ & $M$ & $S D$ & $F$ & $p$ \\
syntactic & 0.53 & 0.730 & 0.83 & 0.747 & 0.80 & 0.805 & 1.399 & $\mathrm{~ns}$ \\
\hline Lexical & 0.53 & 0.629 & 0.63 & 0.809 & 0.37 & 0.615 & 1.144 & $\mathrm{~ns}$ \\
\hline
\end{tabular}

Note: $\left({ }^{*} p<.05\right), n s=$ not significantly different

Table 8 showed the types of syntactic downgraders used across three different request types by higher linguistic level group. It could be observed that students used more syntactic downgraders for medium imposition request (63.33\%). Within the subcategories of syntactic downgraders, 'progressive aspect' (i.e., I'm hoping...) was least used in comparison with other downgraders across request types. 
Table 8. Syntactic downgraders used across request types by higher level group

\begin{tabular}{llll}
\hline Syntactic downgraders & (High) & (Medium) & (Low) \\
& Req. rule-bending & Req. feedback & Req. appointment \\
past tense & $23.33 \%$ & $40.00 \%$ & $40.00 \%$ \\
progressive aspect & $6.67 \%$ & $10.00 \%$ & $10.00 \%$ \\
embedding & $23.33 \%$ & $33.33 \%$ & $30.00 \%$ \\
Total & $40.00 \%$ & $63.33 \%$ & $56.67 \%$ \\
\hline
\end{tabular}

Note: (1) \% indicates the percentage of messages within each request type that contained the type of modification indicated. (2) The total includes all emails with syntactic modifications.

Table 9 showed the types of lexical downgraders used across three request types by higher level group. It could be observed that fewer than half of the students used lexical modifiers to mitigate the force of their requestive acts across all request types. Within the subcategories of lexical downgraders, 'hedges' (i.e., somewhat, somehow, sort of, etc.,) and 'understater' (i.e., a little, a bit, etc.,) were not employed by any subject in any request type. 'Politeness marker' (i.e., please) was used the most in the high imposition request (23.33\%). 'Consultative device' (i.e., Do you think you can..?) was used the most in medium imposition request (23.33\%). In short, the relatively fewer use of lexical downgraders than syntactic downgraders, and particularly, the non-use of certain subcategories such as 'hedges' and 'understater' may imply students' lack of experience or knowledge in their linguistic repertoire of some of these lexical modifiers.

Table 9. Lexical downgraders used across request types by higher level group

\begin{tabular}{llll}
\hline Lexical downgraders & (High) & (Medium) & (Low) \\
& Req. rule-bending & Req. feedback & Req. appointment \\
politeness marker & $23.33 \%$ & $13.33 \%$ & $6.67 \%$ \\
subjectivizer & $3.33 \%$ & $3.33 \%$ & $0.00 \%$ \\
consultative device & $6.67 \%$ & $23.33 \%$ & $13.33 \%$ \\
downtoner & $20.00 \%$ & $10.00 \%$ & $6.67 \%$ \\
understater & $0.00 \%$ & $0.00 \%$ & $0.00 \%$ \\
hedges & $0.00 \%$ & $0.00 \%$ & $0.00 \%$ \\
others & $0.00 \%$ & $13.33 \%$ & $10.00 \%$ \\
Total & $46.67 \%$ & $43.33 \%$ & $30.00 \%$ \\
\hline
\end{tabular}

Note: (1) \% indicates the percentage of messages within each request type that contained the type of modification indicated. (2) The total includes all emails with lexical modifications.

The use of external modifications across different request types could be observed from Table 10 Significant difference was found in the frequency usages of supportive moves used across different request types by higher level group. The result of post hoc analysis further indicated that students used significantly 
more supportive moves for the highest imposition request $(M=4.90)$ than for the lowest imposition request $(\mathrm{M}=3.93)$.

Table 10. Comparison of frequency usages of external modifications across request types by higher level group

\begin{tabular}{l|llllllll}
\hline \multirow{2}{*}{$\begin{array}{l}\text { External } \\
\text { modifica-tio }\end{array}$} & \multicolumn{2}{l}{ Req.rule-bending } & \multicolumn{2}{l}{ Req. feedback } & \multicolumn{2}{l}{ Req. Appt. } & \multicolumn{2}{l}{ ANOVA } \\
\cline { 2 - 9 }$n$ & $M$ & $S D$ & $M$ & $S D$ & $M$ & $S D$ & $F$ & $p$ \\
\cline { 2 - 10 } & $4.90^{\mathrm{a}}$ & 1.27 & 4.23 & 1.65 & $3.93^{\mathrm{b}}$ & 1.26 & 3.716 & $.028^{\star}$ \\
\hline
\end{tabular}

Note: $\left({ }^{*} p<.05\right)$, Means with different alphabet letters differ significantly $\left({ }^{*} p<.05\right)$ by the post hoc Tukey test.

Table 11 showed the types of supportive moves used across request types by higher level group. It could be observed that all subjects used external modifiers to soften the requestive acts across different request types. Within the subcategories, the use of 'grounder' (i.e., reasons, explanations, justifications) could be found across different request types by nearly all participants. Most participants also applied 'acknowledge imposition' $(80.00 \%)$ for highest level imposition (i.e., request for bending rules). But the percentage of this move dropped drastically to $10 \%$ for medium imposition request and to $6.67 \%$ for the lowest imposition request. In short, students applied different types of supportive moves for different imposition levels of e-mail tasks. Among all, the relative low use of 'imposition minimizer' across request types may imply that students were unfamiliar with or did not know how to use this move.

Table 11. Types of supportive moves used across request types by higher level group

\begin{tabular}{llll}
\hline Supportive Moves & (High) & (Medium) & (Low) \\
& Req. rule-bending & Req. feedback & Req. appointment \\
preparator & $16.67 \%$ & $6.67 \%$ & $13.33 \%$ \\
precommitment & $23.33 \%$ & $23.33 \%$ & $6.67 \%$ \\
grounder & $110.00 \%$ & $96.67 \%$ & $103.33 \%$ \\
acknow.imposition & $80.00 \%$ & $10.00 \%$ & $6.67 \%$ \\
promise & $46.67 \%$ & $0.00 \%$ & $16.67 \%$ \\
expectation & $13.33 \%$ & $30.00 \%$ & $23.33 \%$ \\
sweetener & $13.33 \%$ & $60.00 \%$ & $100.00 \%$ \\
apology & $66.67 \%$ & $30.00 \%$ & $30.00 \%$ \\
thanking & $56.67 \%$ & $93.33 \%$ & $53.33 \%$ \\
direct appeal & $26.67 \%$ & $30.00 \%$ & $20.00 \%$ \\
imposition minimi. & $0.00 \%$ & $10.00 \%$ & $3.33 \%$ \\
importance & $13.33 \%$ & $10.00 \%$ & $0.00 \%$ \\
effort & $20.00 \%$ & $10.00 \%$ & $0.00 \%$ \\
giving options & $3.33 \%$ & $13.33 \%$ & $16.67 \%$ \\
Total & $100.00 \%$ & $100.00 \%$ & $100.00 \%$ \\
\hline
\end{tabular}

Note: (1) \% indicates the percentage of messages within each request type that contained the type of 
supportive moves indicated; percentages add up to more than $100 \%$ since supportive moves are not mutually exclusive but can occur together. (2) The total includes all emails with supportive moves.

Apparently, the higher linguistic proficiency students in the current study used the most direct strategies in the highest imposition request. Particularly, they adopted most 'expectation statements' (i.e., I hope that...) as their main requestive act. Query preparatory was used significantly more for medium imposition request, and the same amount of both query preparatory and direct strategies were used for the lowest imposition request. From the questionnaires, students pointed out that direct strategies, particularly 'expectation statements', did not signify impoliteness but allowed for more explicitness and sincerity since its direct Chinese translation resembled humbleness and respectfulness, and their intention could be conveyed more clearly. As for the significantly more use of query preparatory for medium level imposition, the finding suggested that when the compliance of the request was not as critical, students would resort to the conventional indirect strategy modified by internal downgraders to express their requestive intention. More direct strategy use for the highest imposition request found in the current study thus conflicts with the many previous findings in which more query preparatory was used for high imposition request (see Biesenback-Lucas, 2007; Chen, 2000, 2001).

Regarding the use of politeness features, higher proficiency students used more external than internal downgraders, particularly for the highest imposition request. By using lengthy supportive moves prior to the main requstive acts, students believed that they were being more indirect, and thus showing more politeness and respect to their addressee.

4.2 Lower-intermediate Level Group: Directness Levels across Request Types and the Use of Politeness Features

4.2.1 Directness Levels in students' e-mail messages across request types

In comparing the mean numbers of different request strategies in the formulation of different request types by lower level students, the results of ANOVA test were shown on Table 4.8. As indicated, no significantly different uses of request strategies were found across different request types by lower level group students.

Table 12. Comparison of frequency usages of main request strategies across request types by lower level group

\begin{tabular}{lllllllll}
\hline $\begin{array}{l}\text { Request } \\
\text { strategies }\end{array}$ & Req.rule-bending & Req. feedback & Req. Appt. & ANOVA & \\
\hline \multirow{3}{*}{ direct } & $M$ & $S D$ & $M$ & $S D$ & $M$ & $S D$ & $F$ & $p$ \\
query pre. & 0.63 & 0.490 & 0.53 & 0.507 & 0.47 & 0.507 & 1.78 & $\mathrm{~ns}$ \\
\hline hint & 0.07 & 0.466 & 0.47 & 0.507 & 0.53 & 0.507 & 0.84 & $\mathrm{~ns}$ \\
\hline
\end{tabular}

Note. ${ }^{*} p<.05$, ns $=$ not significantly different 
From Table 12, it showed that for highest imposition request, students used most direct strategies (63\%) and least query preparatory (30.00\%). For medium and low level imposition request, students' choices of direct and query strategies, although not varied significantly, showed that as the imposition level increased, more direct strategies and fewer query preparatories were used as their main request strategies.

Table 13 shows the percentage of different subcategories of direct strategies used for different request types. Among all, 'want statements' were the most preferred direct strategy $(53.33 \%)$, closely followed by 'expectation statements' (50.00\%).

Table 13. Subcategories of direct strategies adopted by lower level group across request types

\begin{tabular}{llllllll}
\hline $\begin{array}{l}\text { Request } \\
\text { types }\end{array}$ & Imperatives & Performative & $\begin{array}{l}\text { Direct } \\
\text { questions }\end{array}$ & $\begin{array}{l}\text { Want } \\
\text { statements }\end{array}$ & $\begin{array}{l}\text { Need } \\
\text { statements }\end{array}$ & $\begin{array}{l}\text { Expectation } \\
\text { statements }\end{array}$ & $\begin{array}{l}\text { Total } \\
\text { direct } \\
\text { strategies }\end{array}$ \\
rule-bending & $16.67 \%$ & $6.67 \%$ & $0.00 \%$ & $13.33 \%$ & $3.33 \%$ & $23.33 \%$ & $63.33 \%$ \\
Feedback & $6.67 \%$ & $3.33 \%$ & $0.00 \%$ & $10.00 \%$ & $6.67 \%$ & $26.67 \%$ & $53.33 \%$ \\
Appointment & $6.67 \%$ & $6.67 \%$ & $3.33 \%$ & $30.00 \%$ & $0.00 \%$ & $0.00 \%$ & $46.67 \%$ \\
Total & $30.01 \%$ & $16.67 \%$ & $3.33 \%$ & $53.33 \%$ & $10.00 \%$ & $50.00 \%$ & \\
\hline
\end{tabular}

Note: (1) The total includes all emails with different subcategories of direct strategies across three different request types. (2) Total direct strategies used include all emails contained each request type varied by levels of imposition.

\subsubsection{Politeness features in higher level students' email requests}

(1) Internal modifications: syntactic and lexical downgraders

Table 14 showed the comparison of frequency usages of both syntactic and lexical downgraders used across different request types by lower proficiency level group. As indicated in Table 14, frequency usages of syntactic downgraders were significantly different across different request types. Both Tukey and LSD post-hoc tests were performed to locate the significance, yet only LSD post-hoc test was able to locate the difference since the $p$ value was just slightly smaller than $0.05(p=0.047)$. Specifically, the statistical result showed that the use of syntactic downgraders was significantly less for high imposition request $(M=0.27)$ and more for low imposition request $(M=0.67)$. As for lexical downraders, Table 4.10 showed that they were not used significantly differently across different request types. The result revealed a relative low use of lexical downgraders across different request types by lower level group. 
Table 14. Comparison of frequency usages of internal modifications across request types by lower level group

\begin{tabular}{lllllllll}
\hline $\begin{array}{l}\text { Internal } \\
\text { modifica. }\end{array}$ & Req.rule-bending & Req. feedback & Req. Appt. & ANOVA & \\
\hline & $M$ & $S D$ & $M$ & $S D$ & $M$ & $S D$ & $F$ & $p$ \\
syntactic. & $0.27^{\mathrm{a}}$ & 0.521 & 0.60 & 0.675 & $0.67^{\mathrm{b}}$ & 0.758 & 3.177 & $0.047^{\star}$ \\
\hline Lexical. & 0.37 & 0.490 & 0.23 & 0.430 & 0.17 & 0.379 & 1.640 & $\mathrm{~ns}$ \\
\hline
\end{tabular}

Note: $\left({ }^{*} p<.05\right)$, Means with different alphabet letters within the same category differ significantly $\left({ }^{*} p<.05\right)$ by the post hoc LSD test., ns= not significantly different

Table 15 showed the types of syntactic downgraders used across three different request types by lower proficiency group. It showed that students used significantly more syntactic downgraders for low imposition request $(66.67 \%)$ than high imposition request $(23.33 \%)$. Within the subcategories, 'progressive aspect' was least used in comparison with other downgraders across request types.

Table 15. Syntactic downgraders used across request types by lower level group

\begin{tabular}{llll}
\hline Syntactic downgraders & (High) & (Medium) & (Low) \\
& Req.rule-bending & Req. feedback & Req. appointment \\
past tense & $10.00 \%$ & $40.00 \%$ & $40.00 \%$ \\
progressive aspect & $3.33 \%$ & $3.33 \%$ & $3.33 \%$ \\
embedding & $13.33 \%$ & $16.67 \%$ & $23.33 \%$ \\
Total & $23.33 \%$ & $50.00 \%$ & $66.67 \%$ \\
\hline
\end{tabular}

Note: (1) \% indicates the percentage of messages within each request type that contained the type of modification indicated. (2) The total includes all emails with syntactic modifications.

Table 16. showed the types of lexical downgraders used across three request types by lower level group. In general, very few lexical modifiers were used except for the 'politeness marker'-please. Specifically, 'downtoner' (i.e., possibly, perhaps), 'understater' (i.e., a little, a bit), 'hedges' (i.e., somewhat, somehow, sort of), and other mitigating device (i.e., honor, pleasure) were not used in any request types. 
Table 16. Lexical downgraders used across request types by lower level group

\begin{tabular}{llll}
\hline Lexical & (High) & (Medium) & (Low) \\
downgraders & Req.rule-bending & Req. feedback & Req. appointment \\
politeness marker & $33.33 \%$ & $13.33 \%$ & $6.67 \%$ \\
subjectivizer & $3.33 \%$ & $0.00 \%$ & $3.33 \%$ \\
consultative device & $0.00 \%$ & $0.00 \%$ & $3.33 \%$ \\
downtoner & $0.00 \%$ & $0.00 \%$ & $0.00 \%$ \\
understater & $0.00 \%$ & $0.00 \%$ & $0.00 \%$ \\
hedges & $0.00 \%$ & $0.00 \%$ & $0.00 \%$ \\
others & $0.00 \%$ & $10.00 \%$ & $3.33 \%$ \\
Total & $36.67 \%$ & $23.33 \%$ & $16.67 \%$ \\
\hline
\end{tabular}

Note: (1) \% indicates the percentage of messages within each request type that contained the type of modification indicated. (2) The total includes all emails with lexical modifications.

(2) External modifications:

The use of external modifications across different request types could be observed in Table 4.13. Significant difference was found in the frequency usages of supportive moves across different request types. The result of post hoc analysis further indicated that students used significantly more supportive moves in requesting for bending rule $(M=4.15)$ than in requesting for feedback $(M=3.10)$ and requesting for appointment $(M=3.37)$.

Table 17. Comparison of frequency usages of external modifications across request types by lower level group

\begin{tabular}{lllllllll}
\hline External & \multicolumn{2}{l}{ Req.rule-bending } & \multicolumn{2}{l}{ Req. feedback } & \multicolumn{2}{l}{ Req. Appt. } & \multicolumn{2}{l}{ ANOVA } \\
\cline { 2 - 9 } modifica-tio & $M$ & $S D$ & $M$ & $S D$ & $M$ & $S D$ & $F$ & $p$ \\
\cline { 2 - 10 }$n s$ & $4.15^{\mathrm{a}}$ & 1.14 & $3.10^{\mathrm{b}}$ & 1.09 & $3.37^{\mathrm{b}}$ & 1.00 & 14.256 & $.00^{*}$ \\
\hline
\end{tabular}

Note: ( $\left.{ }^{*} p<.05\right)$, Means with different alphabet letters differ significantly $\left({ }^{*} p<.05\right)$ by the post hoc Tukey test.

Table 18 showed the types of supportive moves used across request types by lower level group students. It could be observed that all subjects used supportive moves to soften the requestive acts across different request types. Within the subcategories, the use of 'grounders' could be found across different request types by all participants. 'Acknowledge imposition' and 'promise' were used by more than half of the participants $(63.33 \%)$ in the highest imposition request, but were not used at all in the lower level imposition requests. The statistical results revealed that as the levels of imposition increased, lower level students used more supportive moves to externally mitigate the illocutionary force of their requestive act, and they also used different types of supportive moves with different request tasks. 
Table 18. Types of supportive moves used across request types by lower level group

\begin{tabular}{llll}
\hline Supportive Moves & (High) & (Medium) & (Low) \\
& Req. rule-bending & Req. feedback & Req. appointment \\
preparator & $6.67 \%$ & $6.67 \%$ & $3.33 \%$ \\
precommitment & $13.33 \%$ & $23.33 \%$ & $6.67 \%$ \\
grounder & $90.00 \%$ & $96.67 \%$ & $93.33 \%$ \\
acknow.imposition & $63.33 \%$ & $0.00 \%$ & $0.00 \%$ \\
promise & $63.33 \%$ & $0.00 \%$ & $0.00 \%$ \\
expectation & $16.67 \%$ & $13.33 \%$ & $16.67 \%$ \\
sweetener & $3.33 \%$ & $26.67 \%$ & $80.00 \%$ \\
apology & $86.67 \%$ & $13.33 \%$ & $6.67 \%$ \\
thanking & $76.67 \%$ & $100.00 \%$ & $80.00 \%$ \\
direct appeal & $16.67 \%$ & $10.00 \%$ & $23.33 \%$ \\
imposition minimi. & $0.00 \%$ & $6.67 \%$ & $3.33 \%$ \\
impotance & $10.00 \%$ & $6.67 \%$ & $3.33 \%$ \\
effort & $3.33 \%$ & $0.00 \%$ & $0.00 \%$ \\
giving options & $0.00 \%$ & $6.67 \%$ & $20.00 \%$ \\
Total & $100.00 \%$ & $100.00 \%$ & $100.00 \%$ \\
\hline
\end{tabular}

Note: (1) \% indicates the percentage of messages within each request type that contained the type of supportive moves indicated; percentages add up to more than $100 \%$ since supportive moves are not mutually exclusive but can occur together. (2) The total includes all emails with supportive moves.

Apparently, for lower linguistic proficiency students in this study, the use of request strategies across request types did not vary significantly, although they tended to use more direct strategies for the highest imposition request, and as the imposition level decreased, more query preparatory was used. Among all direct strategies, 'want statements', 'expectation statements' and 'Please + impositives' were often adopted as requestive head acts. Students pointed out these strategies would sound less ambiguous yet polite, and thus were adopted more frequently for highest imposition request.

As for the use of politeness features, the lower level students used significantly more external than internal downgraders, particularly for the highest imposition request. Similar to the higher level groups, students pointed out the need to be indirect by showing more supportive moves such as 'apology', 'sweenters', and 'grounders' before making the core request. Regarding the relative low use of syntactic and lexical downgraders, the lower proficiency students showed very limited ability in using lexical modifiers, except for 'please', and only 'past tense' in syntactic downgraders was sometimes adopted. This could be explained by the developmental continuum pointed out by Barron (2003) in that lower level students overuse 'please' and underuse other lexical modifiers such as 'downtoners', 'hedges', 'understaters', etc. 


\subsection{Higher-intermediate vs. Lower-intermediate Proficiency Level students}

\subsubsection{Comparison of the directness levels in the realization of request strategies}

As shown in the previous section, both higher-intermediate and lower-intermediate groups used more direct strategies for high imposition request. Table 4.15 displayed the comparison of the mean numbers of the three main request strategies used in all request types between the two groups. As the results of independent t-tests indicated, the two groups did not differ in the realization of main request strategies used in all request types. In general, subjects of both linguistic proficiency levels tended to use more direct strategies and fewer query preparatory as their main request strategies. Hint was indiscriminately rarely used by both groups.

Table 19. Comparison of higher and lower level groups' frequency usages of different request strategies in all request types

\begin{tabular}{l|llllll}
\hline Request strategies & Higher & \multicolumn{5}{l}{$\begin{array}{l}\text { Lower } \\
\text { level group }\end{array}$} \\
& level group & \multicolumn{5}{c}{ t-test } \\
\cline { 2 - 7 } & $M$ & $S D$ & $M$ & $S D$ & $t$ & $p$ \\
Direct strategy & 0.51 & 0.503 & 0.54 & 0.501 & 0.447 & ns \\
Query Preparatory & 0.47 & 0.502 & 0.43 & 0.498 & 0.446 & ns \\
\hline Hint & 0.02 & 0.148 & 0.02 & 0.148 & 0.00 & ns \\
\hline
\end{tabular}

Note: $\left({ }^{*} p<.05\right)$

\subsubsection{Comparison of Politeness Features Used}

(1) Internal modifications

Table 20 showed the comparison of two groups' frequency usages of syntactic and lexical downgraders in all request types. As indicated, the results of independent t-tests showed that higher proficiency group used more syntactic downgraders and significantly more lexical dowgraders in comparison with the lower proficiency group in all request types.

Table 20. Comparison of higher and lower level groups' frequency usages of different internal modifications in

\begin{tabular}{|c|c|c|c|c|c|c|}
\hline \multirow[t]{2}{*}{ Internal modifications } & \multicolumn{2}{|c|}{$\begin{array}{l}\text { Higher } \\
\text { level group }\end{array}$} & \multicolumn{2}{|c|}{$\begin{array}{l}\text { Lower } \\
\text { level group }\end{array}$} & \multicolumn{2}{|l|}{ t-test } \\
\hline & $M$ & $S D$ & $M$ & $S D$ & $t$ & $p$ \\
\hline Syntactic downgraders & 0.72 & 0.765 & 0.52 & 0.674 & 1.964 & $0.051^{\#}$ \\
\hline Lexical downgraders & 0.51 & 0.691 & 0.26 & 0.439 & 2.962 & $0.003^{*}$ \\
\hline
\end{tabular}

Note: $\left({ }^{*} p<.05\right)$, \#Marginally significant

\section{(2) External modifications}

Table 21 showed the comparison of higher and lower level groups' frequency usages of supportive moves in all request types. As indicated, the result of the independent t-test showed that higher level group used 
significantly more supportive moves than the lower level group as the politeness devices to soften the requestive force in their requests.

Table 21. Comparison of higher and lower level groups' frequency usages of supportive moves in all request types

\begin{tabular}{l|lllllll}
\hline External modifications & \multicolumn{4}{l}{$\begin{array}{l}\text { Higher } \\
\text { level group }\end{array}$} & \multicolumn{4}{l}{$\begin{array}{l}\text { Lower } \\
\text { level group }\end{array}$} & \multicolumn{2}{l}{ t-test } \\
\cline { 2 - 7 } & $M$ & $S D$ & $M$ & $S D$ & $t$ & $p$ \\
\hline Supportive moves & 4.36 & 1.448 & 3.66 & 1.229 & 3.497 & $0.001^{*}$ \\
\hline
\end{tabular}

Note: $\left({ }^{*} p<.05\right)$

In comparing the use of direct strategies and politeness features across different request types by the two participating groups, the results showed that their choice of using direct strategies in making high imposition request was the same. As revealed in the interview and questionnaire, this phenomenon had to do with students' insecurity with their linguistic ability, which enforced them to use more explicit and concise, thus more direct requestive acts for the highest imposition request to avoid ambiguity on the addressee, since the consequence of failing or passing was at stake. In addition, both groups did not equate "explicitness and conciseness" with "directness and impoliteness" since the Chinese equivalents of these "direct strategies" were considered humble, indirect, and polite. However, qualitative differences did exist, since higher level group used more politeness devices such as 'past tense' and 'embedding' to internally mitigate the illocutionary force in their request.

As for the politeness features used, in terms of internal downgraders, higher proficiency group used more syntactic modifiers, and significantly more lexical modifiers than lower proficiency group. Thus, as students' linguistic level increased, their adoption of internal modifications would also increase. However, cautions should be made in that some of the internal modifiers such as 'progressive aspect', 'hedges', and 'understaters' were rarely or never used by higher level students. This suggested some of the internal modifiers may not be acquired by mere exposure; explicit teaching might be the key for students to effectively learn these internal devices in making e-polite requests. For the use of external modifications, both groups used most of the supportive moves for the highest imposition request. Higher proficiency level group, with more linguistic repertories, used significantly more numbers and more types of supportive moves than their less proficient counterparts.

\subsection{Qualitative Results}

Qualitative findings could be observed from closer examination of the actual realization of main request strategies, internal and external modifications and how the email discourses were sequenced by the two groups of participants. 


\subsubsection{Comparison of main request strategies used by the two groups}

While looking closely at the actual realization of direct strategies and query preparatory used by the two groups, it could be observed that qualitative differences did exist within the same type of request strategies. For the comparison of requestive head acts, examples of most preferred direct strategy-'expectation statements' and the less adopted strategy 'query preparatory' were listed as follows:

(1) expectation statement:

- If it is possible, I wish Professor Black can take this into account to consider letting me pass the course.(higher proficiency student: embedding, downtoner)

- I hope you can let me pass, please. (lower proficiency student, politeness marker)

(2) query preparatory:

- If there was any possibility, would you please give me one more chance to make up for my absence and pass the course? (higher proficiency student: embedding, past tense)

- Can you let me pass this class? (lower proficiency student)

As examples provided above, the differences in the use of internal modifications such as syntactic downgrader (i.e., 'past tense', 'embedding') and the lexical downgraders (i.e, 'downtoner', 'politeness marker') have made the higher proficiency students' requestive head acts sound less direct and thus, more polite in their perlocutionary effects. In addition, the formulaic expressions such as "if it is possible...", "if there is any possibility", "Would you please...", and "Would it be possible", although not used extensively, started to appear in some higher level students' email request messages, whereas very few of which were used by their less proficient counterparts. Previous research indicated that learners use lower rate of formulas than native speakers (Edmondon \& House, 1991; Bardovi-Harlig, 2006; Blum-Kulka \& Olshtain, 1986). In combing previous findings with the result of the current study in which lower level EFL learners displayed much fewer conventional expressions than the higher level learners, a developmental sequence in the acquisition of formulaic expressions could thus be established.

\subsubsection{Comparison of actual linguistic realization of syntactic and lexical downgraders by two groups}

Quantitative results showed that higher proficiency level students used more syntactic modifiers and significantly more lexical modifiers than lower level group. For the comparison of actual realization of internal modifications used by the two groups, examples are provided below.

\section{Past tense:}

- Could you please give me a few minutes to talk about this course? (higher proficiency student)

- Can you arrange an appointment in getting some advice for me, please? (lower proficiency student)

\section{Embedding:}

- I'm writing to ask if it is possible for me to see you in your office hour.... (higher proficiency student) 
- I want to ask you if I can request for an appointment in your office hour... (lower proficiency student)

\section{Politeness marker- please:}

- Would you please give me one more chance?

(higher proficiency student)

- Please give me one more chance to pass this course.

( ower proficiency student)

As shown in first examples provided above, although the use of 'politeness marker'-please, was the mostly adopted lexical modifier by both groups, it was realized differently by the two groups. From the examples, although the same type of lexical device (i.e., please) was used, the higher proficiency students used it in the embedded position of the sentence while the lower proficiency students used it as the most direct strategy"Please + imperative". As indicated by Blum-Kulk (1991) and Barron (2003), the use of please in the embedded position of the sentence reflected the native speakers' preference. The higher level students thus demonstrated their expanded pragmalinguistic repertoire in using this device in a more native like manner.

For the syntactic device- 'embedding', higher proficiency students showed their embedded sentence as a formulaic expression (i.e, l'm writing to ask if it is possible...), whereas lower level student filled their embedded sentence with more trace of direct L1 transfer (i.e., I want to ask you if I can request for an appointment in your office hour...). Although analysis of perspective was not the focus of the current study, Ellis (1997) and Trosborg (1995) identified the developmental patterns in which beginning learners often adopted a "hearer perspective" ( i.e., Can you....) in making request and as their level of linguistic proficiency advanced, more "speaker perspective" requests were formulated (i.e., Can I...). As for the "impersonal perspective" (i.e., Is it possible...), native speakers in their study had significantly greater use of 'impersonative perspective' (Ellis, 1997; Trosborg, 1995). The example provided above thus mirrored the developmental patterns identified from previous research.

\subsubsection{Comparison of positions of external modifiers}

Supportive moves are external to the head act, occurring either before or after it, and serve the function of mitigating the requested act (Blum-Kulka, House, \& Kasper, 1989). Quantitative findings earlier revealed that the higher level group employed significantly more numbers and more types of supportive moves than the lower level group, while most supportive moves were used for the highest imposition request for both groups. Qualitative result here focused on the position of supportive moves employed by the participating students. Table 22 showed the position of supportive moves used in all the emails by the two groups. 
Table 22. Position of supportive moves by two groups

\begin{tabular}{lll}
\hline Position of supportive moves & $\begin{array}{l}\text { Higher level group } \\
\text { (90 email messages) }\end{array}$ & $\begin{array}{l}\text { Lower level group } \\
\text { (90 email messages) }\end{array}$ \\
\hline Pre-request move & $34(37.8 \%)$ & $47(52.2 \%)$ \\
Post-request move & $7(7.8 \%)$ & $3(3.3 \%)$ \\
\hline Both pre-and post-moves & $49(54.4 \%)$ & $40(44.4 \%)$ \\
\hline
\end{tabular}

For the position of supportive moves, Table 4.26 indicated that both groups preferred the use of both prerequest, and pre- and post- supportive moves. A closer look at the comparison between the two mostly used moves, the higher level group used more pre- and post- supportive moves (54.4\%) than pre- request moves $(37.8 \%)$; whereas the lower level group used more pre- request moves $(52.2 \%)$ than pre- and post- request moves (44.4\%). From the interview, higher level students revealed that the use of both pre- and post- moves as an even more polite strategy than using pre- request moves alone since they could elaborate more to express their politeness through external devices in their requests. It's not hard to understand that lower level students were limited by their linguistic resources, and thus adopted more pre- moves to avoid making language mistakes.

From these preferred position of moves, both pre- and pre- and post- supportive moves, it should be noted that 'grounders' were always used before the requestive acts. In other words, the reasons or justifications were always stated first before the actual requestive act was made. Kirkpatrick (1991) analyzed the structure of 40 Chinese letters of requests written to the China Section of Radio Australia, and found that Chinese indirectness and politeness was established by "because--- therefore" sequence rather than "therefore-- because" structure. The use of pre- grounders by subjects in the current study also followed the "because--therefore" sequence and thus the result echoed with the previous study.

\subsubsection{Factors which influence students' choice of linguistic politeness strategies in emails}

Based on the findings from the questionnaires and interviews, factors which influence students' choice of linguistic politeness strategies could be approached from the following perspectives: (1) situational factor; (2) linguistic proficiency; and (3) transfer of $\mathrm{L} 1$ pragmatic knowledge. They were discussed as follows:

(1) Situational factor: imposition level of the request

From the questionnaire and retrospective interview, the majority of students' perceived levels of imposition on three email tasks corresponded to the imposition levels originally designed. Most students specified that the most indirect strategy should be used for the highest imposition email request. However, from the actual realization of their request, the direct strategies were most frequently used for the highest level imposition request by both groups. Particularly, 'expectation statements' (i.e., I hope that...) were used extensively by both groups, and 'want statements' (i.e., I would like to/ want to...) were the other greatly used direct strategy by the 
lower level group. Students pointed out in the interview that these two strategies were polite ways to address their requests. The Chinese equivalents of "I hope ...", "Wo-Xiwang..." and "I want/ would like to", "Wo-Xiang", were perceived as very polite strategies for them since the same realizations of both strategies were very modest and humble in Chinese. In addition, the most adopted 'expectation statements' (e.g., I hope that you...) often combined both direct and indirect elements, "in which the hope expressed is itself a conventionally indirect request that refers to the hearer's ability or willingness" (Yu, 1999, p. 300). Students thus considered these strategies as being indirect, rather than direct strategies as they appeared on the CCSARP scale.

(2) Linguistic proficiency

Both groups addressed their difficulties in making e-mail request in the writing tasks. Most students specified their worrisome about improper word use which might lead to misunderstanding or negative perception on their professors. Some higher proficiency students pointed out that they found it difficult to make their email requests clear and at the same time polite. As for the lower level students, their perceived difficulties mainly came from their limited knowledge of English grammar and word usages. In general, higher level students concerned more about the pragmatic appropriateness, whereas lower level students worried about their linguistic problems in writing a proper email request. To overcome the limited capability in related pragmatic norms, the higher level students, with relatively more linguistic resources, tended to elaborate more by using more supportive moves, which might lead to verbosity and cause negative perlocution on their addressee. As for the lower level students, their limited capacity in both linguistic and pragmatic knowledge had hindered their attempts in using some English structures or expressions they were unsure of in order to "play safe" in avoiding making too many mistakes.

(3) Transfer of L1 pragmatic knowledge

Students from both groups indicated that they would resort to their existed L1 pragmatic knowledge of politeness in composing these emails since they were not familiar with the norm and context of making English request to professors. Most of the students also mentioned that they were using the "Chinese way" in composing these email requests by giving reasons prior to requests and by using different types of supportive moves to show their sincerity and respect. Zhang (1995b) pointed out that "to define indirectness in Chinese and to realize it in interaction, external modification of utterances is mandatory, internal modification is not" (p.82). The result of the current study thus echoed Zhang's findings.

\section{Conclusions and discussions}

This study intends to explore Taiwanese EFL Learners' pragmatic competence in the production of email request to professors in the institutional setting. It sets to find out the preferred use of request strategies, the internal and external modifications, and the information sequencing of the email messages by the two linguistic level groups while writing email requests to their professors with varied degrees of imposition. The findings pointed out that both higher and lower linguistic groups preferred to use direct strategies in making high 
imposition email request. This phenomenon revealed that students' preference in making their requestive head acts more explicit and concise, and seemingly more direct (according to CCSARP scale) in order to avoid ambiguity on the addressee, since the consequence of failing or passing the course was at stake. It should be noted that students' perceptions regarding 'expectation statements' (i.e., I hope that you...) were neither direct nor impolite since such request statements showed concerns for the hearer's ability or willingness and were thus regarded a conventionally indirect request (Yu, 1999). It could also be inferred that at this stage of the interpragmatic development, both groups were still strongly influenced by their L1 pragmatics since the conventional request strategies were not their main choices for the highest imposition task in making proper email requests in the target language.

As for the politeness features used, the result pointed out that as students' linguistic level increased, their adoption of internal and external modifiers also increased accordingly, indicating the developmental sequences in the acquisition of the politeness features. However, since some of the internal modifiers were never used by even higher proficiency groups, it revealed that these devices may not be acquired by mere exposure; explicit teaching might be the key for students to learn these politeness features effectively. Regarding the use of supportive moves, both groups preferred the inductive move pattern ("justification-request") which may not agree with the deductive move pattern ("request-justification") preferred by the native Anglo-American culture (Kong, 1998). Since this may thus cause confusion or negative perception on the recipients of the target language, explicit instruction would be useful in clarifying the different writing rhetoric across different cultures.

As revealed by the questionnaire and interviews, students believed that being indirect was considered as the most respectful way of showing politeness and it was manifested largely via the use of "expectation statement" and pre-posed supportive moves. In addition, students were also aware that they were using Chinese rhetoric particularly in the patterns of supportive moves. However, when lacking contextual knowledge in making proper English email request to professors, they could only resort to their existing L1 pragmatics. Thus, what constitutes the polite head act and the proper use of diverse internal and external strategies should be made explicit in the language classroom, so students could be equipped with effective means to make effective upward email request.

This paper has its limitations in several aspects. First, the subjects were limited to Taiwanese EFL students, and hence, conclusions drawn upon may have its limited application. Secondly, since the subjects participated in this study were of only two linguistic levels, the developmental features of their interlanguage pragmatics could only reflect the partial developmental continuum in this regard. Thus, future research which involves subjects from different linguistic levels is suggested. Being able to write polite as well as appropriate request emails to professors would equip students with another effective medium to interact with professors (Biesenbach-Lucas, 2005). When EFL students are made aware of which request types and politeness devices are proper to use when interacting with professors via e-mail, and are explicitly taught the possible perlocutionary effect of their request strategies, their chances to gain positive feedback will thus increase, leading to better chances for to succeed in academic settings. 


\section{References}

Bardovi-Harlig, K. (2001). Evaluating the empirical evidence: Grounds for instruction in pragmatics? In K. R. Rose \& G. Kasper (Eds.) Pragmatics in Language Teaching Cambridge: Cambridge University Press. pp. 13-32.

Bardovi-Harlig, K. (2006). On the role of formulas in the acquisition of L2 pragmatics. In K. Bardovi-Harlig, C. Felix-Brasdefer, \& A.S. Omar (Eds.), Pragmatics and language learning. Honolulu: University of Hawai, National Foreign Language Resource Center, 11,1-28.

Barron, A. (2003). Acquisition in interlanguage pragmatics: Learning how to do things with words in a study abroad context. Amsterdam: John Benjamins

Beebe, L. \& Takahashi, T. (1989). Do you have a bag?: Social status and patterned variation in second language acquisition. In S. Gass, C. Madden, D. Preston, and L. Selinker (Eds.), Variation in second language acquisition: Discourse and pragmatics (pp. 75-93). Clevedon: Multilingual Matters.

Biesenbach-Lucas, S. (2005). Communication topics and strategies in email consultation: Comparison between American and international university students. Language Learning \& Technology, 9(2), 24-46

Biesenbach-Lucas, S. (2006a). Making requests in email: Do cyber-consultations entail directness? Toward conventions in a new medium. In K. Bardovi-Harlig, J.C. Felix-Brasdefer, \& A. Omar (Eds.), Pragmatics and language learning (pp. 81-108). Honolulu, HI: Second Language Teaching and Curriculum Center, University of Hawai.

Biesenbach-Lucas, S. (2007). Students writing emails to faculty: An examination of e-politeness among native and non-native speakers of English. Language Learning \& Technology, 11(2), 59-81

Blum-Kulka, S. (1991).Interlanguage pragmatics: The case of requests. In R. Phillipson,

E. Kellerman, L, Selinker, M.S. Smith \& M. Swain (Eds.), Foreign/second Language pedagogy research: A commemorative volume for Claus Faerch. Clevedon, UK: Multiligual Matters. pp. 255-272

Blum-Kulka, S., \& Olshtain, E. (1986). Too many words: Length of utterance and pragmatic failure. Studies in Second Language Acquisition, 8, 47-61

Blum-Kulka, S., House, J., \& Kasper, G. (1989). Cross-cultural Pragmatics: Requests and Apologies. Norwood, $\mathrm{NJ}$ : Ablex Publishing Corporation.

Chapman, D. (1997). A comparison of oral and e-mail discourse in Japanese as a second language. On-Call, $11,31-39$

Chen, C-F. E. (2001) Making e-mail requests to professors: Taiwanese vs American students. Paper presented at the Annual Meeting of the American Association for Applied Linguistics, St-Louis, MO. (ERIC Document Reproduction Service No. ED 461 299).

Chen, C-F. E. (2006). The development of e-mail literacy: From writing to peers to writing to authority figures. Language Learning \& Technology, 10(2), 35-55 
Cohen, A.D., \& Olshtain, E. (1981). Developing a measure of sociocultural competence: The case of apology. Language Learning, 31(1), 113-134

Edmondson, W., \& House, J. (1991). Do learners talk too much? The waffle phenomenon in interlanguage pragmatics.In R. Phillipson, E. Kellerman, L. Selinker, M. Sharwood Smith, \& M. Swain (Eds.), Foreign/ second language pedagogy research: A commemorative vlume for Claus Faerch. Clevedon, UK: Multilingual Matters. pp. 273-287

Ellis, R. (1997). SLA research and language teaching. Oxford: Oxford University Press.

Gonzalez- Bueno, M. (1998). The effects of electronic mail on Spanish L2 discourse. Language Learning and Technology, 1, 55-70.

Hartford, B. S., \& Bardovi-Harlig, K. (1996). At your earliest convenience: A study of written student requests to faculty. In L. F. Bouton, (Eds.), Pragmatics and language learning, 7, 55-71.

Hymes, D. (1979). On communicative competence. In C. J. Brumfit \& K. Johnson, (Eds.), The communicative approach to language teaching. Oxford University Press. pp. 1-26

Kasper, G. (1992). Pragmatic transfer. Second Language Research, 8(3), 203-231

Kasper, G., \& Dahl, M. (1991). Research methods in interlanguage pragmatics. Studies in Second Language Acquisition, 13, 215-247

Kirkpatric, A. (1991). Information sequencing in Mandarin in letters of request. Anthropological Linguistics, 33, 183-203

Kong, K. C. C. (1998). Are simple business request letters really simple? A comparison of Chinese and English business request letters. Text, 18, 103-141

Siu. K. P. (2008). Exploring the pragmatic competence of EFL learners in the production and judgement of Formal Written Requests. Doctoral dissertation. Macquarie University, Australia.

Takahashi, S. (1996). Pragmatic transferability. Studies in Second Language Acquisition, 18, 189-223

Tanaka, N. (1988). Politeness: Some problems for Japanese speakers of English. JALT Journal, 9, 81-102

Thomas, J. (1983). Cross-cultural pragmatics failure. Applied Linguistics, 4, 91-112

Trosborg, A. (1987). Apology strategies in native/non-natives. Journal of pragmatics, 11, 147-167

Trosborg, A. (1995). Interlanguage pragmatics: Requests, complaints, and apologies. New York: Mouton de Guyter.

Warschauer, M. (1999). Electronic literacies: Language, culture, ad power in online education. Mahwah, NJ: Lawrence Erlbaum Associates.

Yu, M.C. (1999). Universalistic and culture-specific perspectives on variation the acquisition of pragmatic competence in a second language. Pragmatics, 9(2), 282-312 
Chia-Ti Heather Tseng

Zhang, Y. (1995b). Indirectness in Chinese requesting. In G. Kasper (Eds.), Pragmatics of Chinese as native and target Language. Honolulu: University of Hawaii Press. pp. 69-118

Received: 01/03/2016

Accepted: 15/05/2016 